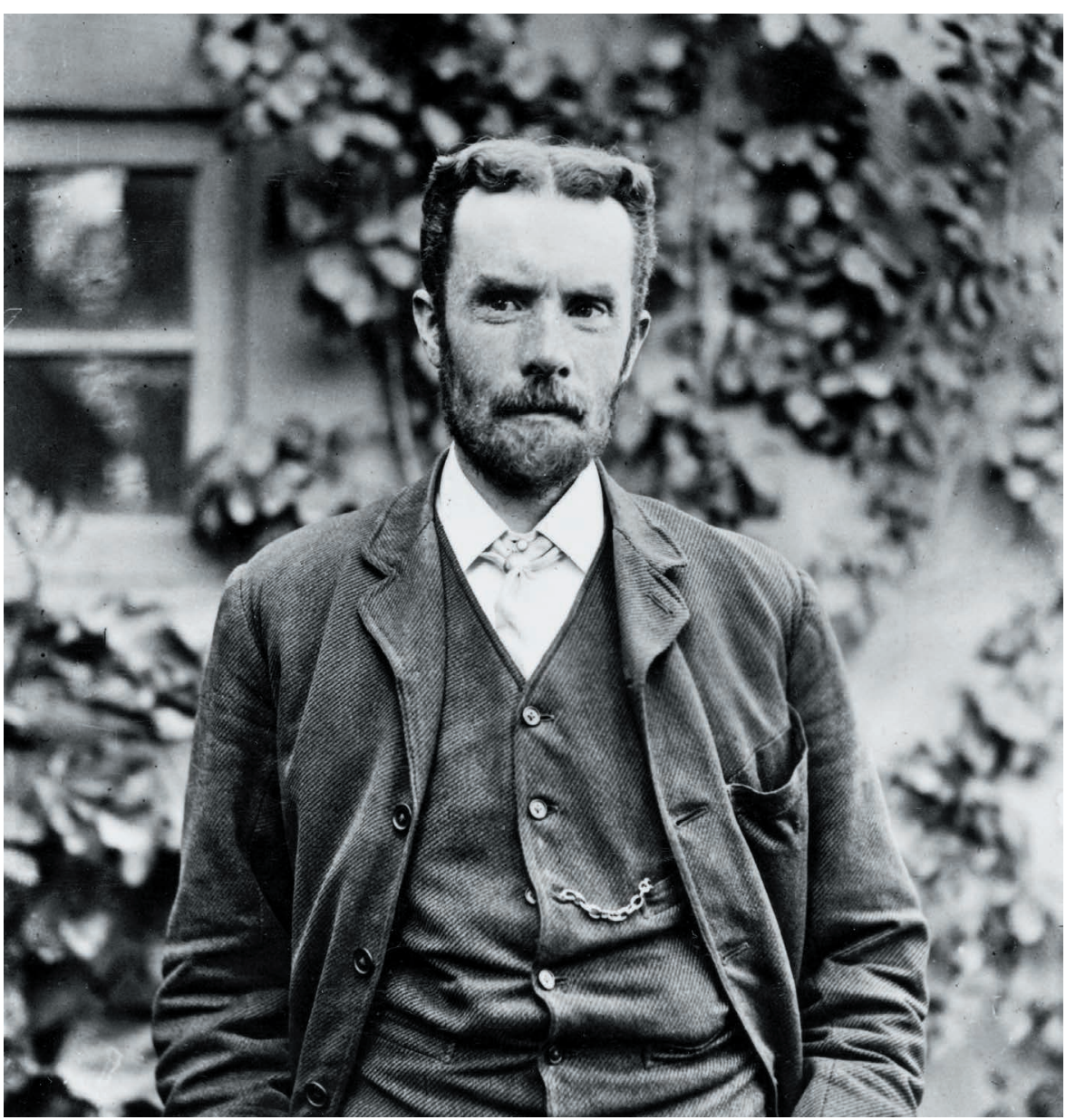

Oliver Heaviside's work is still used by electrical engineers.

ENGINEERING

\title{
Reclusive genius who connected the world
}

\section{W. Bernard Carlson relishes a biography of a self-taught engineer who revolutionized telecommunications.}

$\mathrm{Y}$ ou know you're in an electricalengineering department when you encounter students wearing T-shirts depicting four differential equations. They will tell you that these equations are named after nineteenth-century physicist James Clerk Maxwell, who used them to formulate a unified theory of light, electricity and magnetism.

Today, Maxwell's equations are used to solve practical problems in electronics and telecommunications. But why do they look the way they do? In his 1865 treatise 'A dynamical theory of the electromagnetic field', Maxwell laid out 20 equations using esoteric mathematical expressions known as quaternions. How did the 20 become 4, expressed in simpler The Forgotten vector terminol- Genius of Oliver ogy? Who converted Heaviside: A Maxwell's theory into Maverick of Electrical Science. practical equations? In BASIL MAHON The Forgotten Genius Prometheus: 2017. of Oliver Heaviside, electrical engineer Basil Mahon provides the answer.

As Mahon shows, Heaviside (1850-1925) was a self-educated recluse who invented his own mathematical terminology. He worked at the intersection of engineering practice, academic physics and abstract mathematics, and wrote papers that confounded all three audiences. Throughout his life, he refused to join the scientific community, but by the 1910s, engineers were applying his approach to knotty communication problems. Heaviside's ideas came to be central to modern electrical engineering.

Heaviside was born in London's Camden Town. Like his contemporary, US inventor Thomas Edison, he contracted scarlet fever as a child, leaving him partially deaf. His father, an engraver, struggled to maintain middle-class status as printing technology rapidly evolved; thus Heaviside, although an excellent student, had to leave grammar school and go to work at 16 .

By a stroke of fortune, Heaviside's aunt was married to Charles Wheatstone, an expert in electromagnetism and co-inventor of a successful telegraph system. Wheatstone secured a position for his nephew with the Danish-Norwegian-English Telegraph Company in 1868 . The company was just then laying a cable between Britain and Denmark, and Heaviside learnt at first hand the challenges of getting a new line up and running. Puzzled by the fact that the cable sent messages more efficiently in one direction than the other, Heaviside used mathematics to understand how the signals travelled.

To develop a complete theory of transmission lines, he left his job and moved in with his brother's family. He soon showed that by distributing the line's inductance uniformly, it was possible to diminish both the signal's attenuation and its distortion. To attract attention to his work, Heaviside boldly sent an early publication to the leading physicist William Thomson, who praised it. Yet the same work infuriated influential engineers such as William Preece, who blackballed him and tried to deny him membership of the Society of Telegraph Engineers.

Although squarely outside the professional community, Heaviside persevered and published a stream of papers in the 1880 s and 1890 s, many in the trade journal The Electrician, which paid him $£ 40$ per year. (He also published in Nature.) Despite this meagre income, he managed to recast Maxwell's equations, introducing vectors to represent the magnitude and direction of electrical and magnetic fields. To permit differential equations related to vectors to be solved using algebra, he also deployed operational calculus. Although dense, his papers were appreciated by scientists such as Oliver Lodge, George FitzGerald and Heinrich Hertz, all of whom corresponded with him.

In the late 1890s, as Guglielmo Marconi and Nikola Tesla were investigating wireless telegraphy, theoreticians puzzled about the propagation of radio waves. For Maxwell, radio waves were the same as light waves, and both travelled in straight lines; yet radio waves didn't race off into space, but instead seemed to follow Earth's curvature. Why? In 1902, Heaviside theorized - at the same 
time as US engineer Arthur Kennelly — that radio waves propagated around the world because they bounced off a layer of charged gas particles in the ionosphere. Experimentally confirmed in the 1920s, this reflective portion is now known as the KennellyHeaviside layer.

The importance of Heaviside's work was recognized, but he received no compensation from practical applications. A case in point was the long-distance telephone network built by the American Telephone and Telegraphy Company (AT\&T). AT\&T asked engineers George Campbell and Michael Pupin to study Heaviside's papers on transmission lines. Using his mathematics, they designed inductive loading coils, enabling calls to be made from New York to San Francisco, California, by 1915. They became wealthy from their patents. AT\&T offered to pay Heaviside for his early contribution, but he insisted that he be given full credit for using induction coils on transmission lines. When AT\&T proved unwilling to do this, Heaviside refused to take the money.

Heaviside's scientific peers, however, eventually recognized his contributions, making him a fellow of the Royal Society; the Institution of Electrical Engineers bestowed its Faraday Medal on him. Still embittered by his experience with the Society of Telegraph Engineers, Heaviside turned his back on it all. He spent his final years living modestly in Devonshire and died in 1925.

Drawing on his previous works, such as the Maxwell biography The Man Who Changed Everything (Wiley, 2003), Mahon superbly explains Heaviside's ideas and how they came to define electrical engineering. He deftly pieces together, from letters and notebooks, the scant details we have about Heaviside's personal life. In Mahon's hands, the story resembles a play by Henrik Ibsen, with an angry, complex central character whose life plays out in difficult family relationships. Yet ultimately, Mahon struggles to illuminate the inner Heaviside, and I was left wondering what motivated this extraordinary engineer to pursue the mathematical rendering of electricity with such intensity. What prompted the young telegrapher to dig so deeply into esoteric theory and mathematics, and to isolate himself from people?

Today's electronic technology — and all it implies in terms of global communication and corporate wealth - owes much to Heaviside's brilliant work. Mahon reminds us that such brilliance is often the result of isolation, sacrifice and sheer dogged persistence.

W. Bernard Carlson is Vaughan Professor of Humanities at the University of Virginia, Charlottesville, and author of Tesla: Inventor of the Electrical Age. e-mail:wc4p@virginia.edu

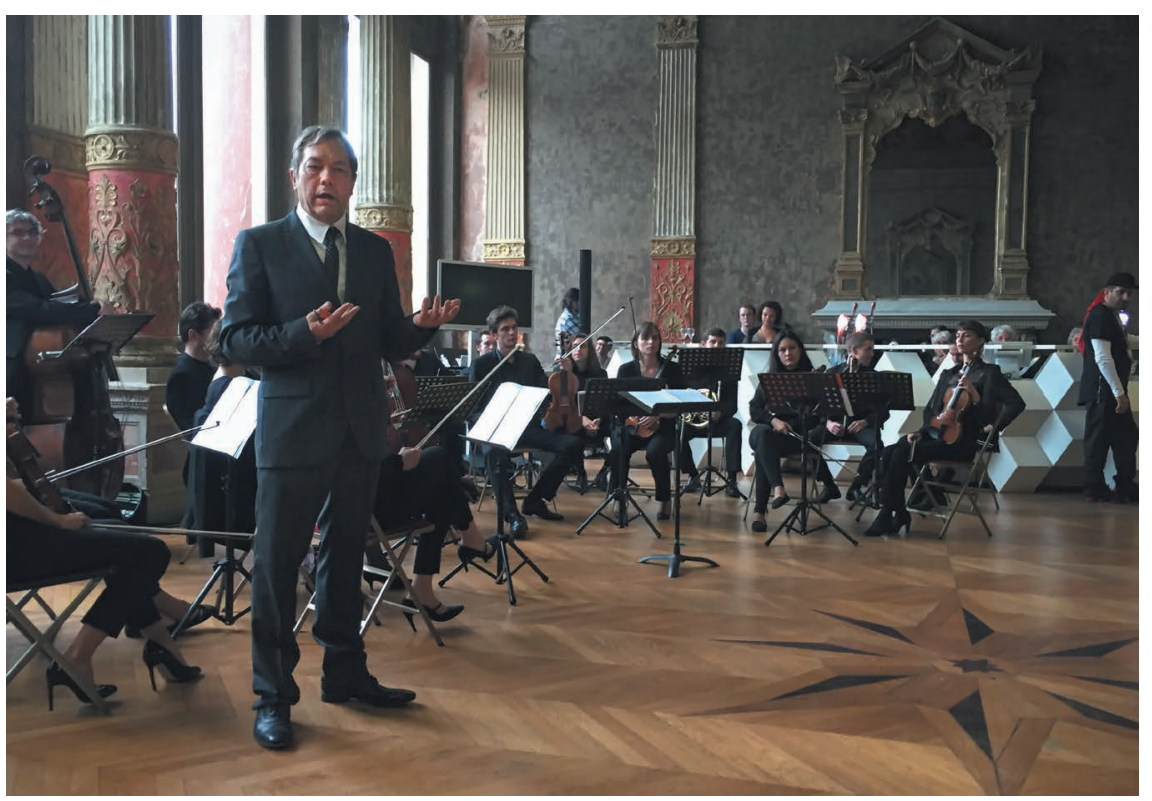

Luc Steels presents an extract of Fausto at the Gaîté Lyrique theatre in Paris.

\section{Q\&A Luc Steels}

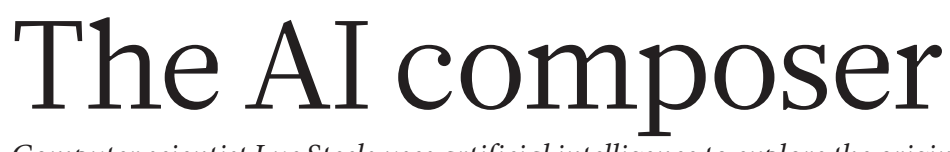

Computer scientist Luc Steels uses artificial intelligence to explore the origins and evolution of language. He is best known for his 1999-2001 Talking Heads Experiment, in which robots had to construct a language from scratch to communicate with each other. Now Steels, who works at the Free University of Brussels (VUB), has composed an opera based on the legend of Faust, with a twenty-first-century twist. He talks about Mozart as a nascent computer programmer, how music maps onto language, and the blurred boundaries of a digitized world.

Is there a relationship between computer science and music?

A lot of computer scientists are interested in music. I think it has to do with the ability to think abstractly. Musical composition is a lot like parallel programming. You have to organize complex material in time, and convey meaning - if, like me, you believe that is what music should do. You have to build a multidimensional abstract object, and that requires an understanding of the physical properties of instruments or voices. Both music and computer science demand the ability to combine high-level imagination with very practical, technical skills. Wolfgang Amadeus Mozart, I think, had the brain of a computer programmer - albeit an exceptional one.

\section{Why opera?}

I had wanted to write an opera for a long time, but there was research to do, labs to run. In 2011, at the Institute for Evolutionary Biology in Barcelona, Spain, I was exploring how evolutionary thinking could shed light on the origins of language. Next
Fausto

Premieres

18 September at

La Monnaie, Brussels.

Public performance

at the And\& Summit/

Festival in Leuven,

Belgium, in May 2018.

the score. I hear the music in my head, then I try to recreate it mentally to pin down what each instrument should be playing. I choose a harmonic framework and a rhythmic structure, and I fill in each instrument's contribution, using the computer as an editing tool until the music resembles what I heard originally. Our first opera, Casparo, tells the tale of a robot that achieves human intelligence, and premiered in Barcelona in 2011.

\section{Has your work on the origins of language} fed into your music?

With both, I'm exploring how meaning gets expressed. One way is through syntax. You change the meaning of a sentence by swapping the subject and object. Something similar is true of music: a certain chord, 